\title{
Working the Field with Oral History: Talking Towards the Research Encounter in Theatre and Performance Studies
}

\section{Lara Nielsen ${ }^{1}$}

When I began teaching within the auspices of a drama department some years ago, I wondered: how does this curricular structure imagine the student of theatre and performance? How does it initiate students into the field? Can there be something new in the practice of theatre and performance studies, in its curricular modules and methodologies of instruction, to nurture the energetic connections between its practical and scholarly components? Whether faced with the propinquities of BFA or BA degree programs, these questions are pivotal for developing talent, teaching, and leadership in the interdisciplinary fields of theatre and performance. It is not just that institutional structures consistently illuminate a familiar division of labor among the faculty or in turn reproduce that old sequencing in students, who sense that they can safely care either about scholarly or practical study (as if those divisions made any sense), but not so easily accommodate both identities in their work. In this way, curricular concerns are as institutionalizing as they are pedagogical. Students are always grappling with what those distinctions might mean as they navigate their own imaginations of what they might $d o$; the quality of these negotiations, in turn, impacts not only how our students apprehend the field, but how they invent its future possibilities. As a process of initiation, an education in theatre and performance typically introduces students to the protocols of authority that define the distinctive paradigms and powers of the field, here appended as acts of making performances versus critical thinking about them, "as though studies were theory and the arts were practice." Curriculum development has always been one of the mechanisms to articulate and develop shifts in the organization of the field and its methodologies at the local level - sometimes, as those with an appetite for departmental histories know, with epochal struggle. Whether or not faculty choose to deliberate upon it, curricula elaborate theoretical agendas. Within the international theatre and performance studies community there is real commitment to the 1995 recommendation by J. Ellen Gainor and Ron Wilson that "educators need to reinforce performance considerations so that historical, theoretical, or strictly textual analysis do[es] not lose sight of the importance of artistic elements; and so that active, production-related components such as acting, directing, and

Lara D. Nielsen is Assistant Professor in Theatre and Dance at Macalester College. She specializes in critical theory; gender, feminist, and postcolonial studies; orality, ethnography, and multimedia documentary methodologies; and avant-garde events. She is published in Performance Research, Women \& Performance, Contemporary Theatre Review, Theatre Journal, TDR, and Journal of Law, Culture, and the Humanities. Her first manuscript, Sacrifice Plays, addresses the modernist détentes of globalization and Latino performance in major league baseball. She is also co-editing an anthology on theatre, performance, and neoliberalism. 
design regain balance with the spectatorial position. ${ }^{{ }^{\prime 3}}$ With a sideways glance, however, the diagnosis still tilts, here and there, into a state of emergency revealing the repetitions of that familiarly hierarchical, and sometimes bipolar pedagogical structure - academia on one side and artistic activities on the other - proscribing the possibilities of the field at its pedagogical and institutionalizing sites of inception. ${ }^{4}$ Meanwhile, other fields do their best to profile performance in their classes, but with varying degrees of collaboration with theatre and performance arts faculties and departments. For students and faculty alike, these can be delicate initiations.

When I began teaching in the Department of Drama at New York University's Tisch School of the Arts, I was lucky enough to be working with colleagues who were keenly attuned to the need to address the artistic research environment, particularly in a BFA context. ${ }^{5}$ NYU's department promises to deliver a "combination of rigorous conservatory training and broad-ranging academic education." ${ }^{\prime \prime}$ I listened to Drama majors remark about the powerful gaps they felt between the languages, purposes, and cultures of the artistic and academic research environments they found themselves in, and I wondered, what kinds of working and dwelling spaces do such testimonies map? What languages and cultures, what research environments? How do students navigate those ideological environments, those grids of power and artistic authorization? A conversation with colleague Jan Cohen-Cruz about artistic practices in the studio cultures my students were immersed in - for example the companies of Stella Adler, Lee Strasberg, or the Experimental Theatre Wingconfirmed the pedagogical challenge for me. "They're oral traditions," she said. To account for the idioms, literatures, theories, and practices that constitute the nuclei of research encounters in the studios of theatre and performance- and in conjunction with the classroom knowledges of theatre and performance studies in the university environment - I had to find a methodical way to help students engage with the spoken as well as printed practices and traditions that students were exposed to in their truly challenging interdisciplinary studies of theatre and performance. In order to address such ambitions even as students were immersed in their fields, I began teaching a course, "The Oral History Project," which would allow students a forum to examine the full interdiscipinarity of their research as actors, directors, designers, and scholars.

As an advanced research seminar, the course suggested three things. First, that artistic (not just "student") work is always interdisciplinary; and second, that oral history would be our method for better apprehending the interdisciplinarity of their artistic research environments at this juncture in their careers. Perhaps most important is the third, implicit suggestion, that with this course we would be in a position to reflect upon the ideological frameworks that organize student activities within the field at large. ${ }^{7}$ Whether students were apprentice technical designers, choreographers, or developing their own experimental performances, in this class students would examine their own pathways between the territories of studio and 
scholarly practices. Such examinations required scholarly research about artistic practices (say, Strasberg or Grotowski), in conjunction with their manifestations within local research frameworks, involving both studio and "academic" kinds of data. I found that students needed the curricular opportunity to pursue sustained research, conversations, reflections, and evaluations about their crafts and the mentoring to assist them in doing so. Using oral history as a method of research suggested the promise of reterritorializing student pathways of thinking that might help them negotiate their own places within the institutions of the performing arts.

My own position is clear: I am an academic. Whether at NYU (or at Macalester College, where I now teach the course) I am located in the Theatre and Performance Studies side of the department, and I mean to develop an "inquiry into the ideological environment in which we are teaching theatre, and a challenge to those who teach it.” Branislav Jakovljevic and his collaborators stress:

By "ideology" we are not referring to the sitting ducks of cultural criticism: race, class, and gender. Instead [. . .] ideology in the most basic sense of the word: as a rational legitimization of the existing order and a tacit agreement in which everyone is involved: politicians and venture capitalists, administrators and professors, students and their parents. ${ }^{8}$

In effect, the pathways of professionalization in theatre and performance point towards ideological models that pressure and scar students and faculties alike. For many, these are deeply experienced conceptual violences that traumatize the field and its place in the realm of the social, including educational institutions. In Professing Performance (2004), Shannon Jackson examines more than a century of institutionalizing histories of theatre and performance studies within U.S. university settings, to understand the repeating conundrums. Jackson identifies the perfect storm that continues to tear at all vessels of theatre and performance studies. She names three simultaneous components that continue to challenge the field. First, the professionalization of literature, which in the early twentieth century "was in danger of not faring very well" and hence found disciplinary-expanding forays into its literature-based territories threatening. Secondly, the feminization of performance as a cultural practice is itself understood by many to be a lesser craft than the masculinist domains of scholarship, playwriting, or design. The third powerbase in Jackson's proverbial storm is the engineering emphasis of technical theatre, further complicating the matrices of theatre and performance pedagogies. In the context of Jackson's narrative, we can begin to appreciate the symptoms and antagonisms that face students and faculties. Although those three ideological pathways continue to define and delimit the field, theatre and performance studies need not simply repeat the repressions of old ideological habits and their epistemological failures. ${ }^{9}$ 
Rather, it is appropriate to ask "about institutions and how they enable or obstruct the production of certain knowledges"10 and about how to make changes. With "The Oral History Project" the hope is to continue that assessment through local contemporary student work.

\section{Towards Practice-based Research:}

\section{Narrative Attitude and The Oral History Project}

A discussion of Alessandro Portelli's concept of narrative attitude that has become so crucial for the oral historian is helpful in reviewing the student use of oral history in this class project. Undergraduates, graduate students, and faculty alike may find the narrative attitude of oral history techniques useful, and for different reasons, but for the moment I am concerned with the disciplinary beginnings of the undergraduate experience. I use oral history in order to help students recognize that they are participants in their own research activities. By way of definition, an oral history is always a living history produced through the auspices of a shared authority: interviews, conversations, talk. Interviewers and interviewees alike are narrators, and what emerges between them is a shared, multivocal, and indeed performative text. This positioning of the (student) subject in knowledge production has the potential to engage, if not dismantle, hierarchical claims to objective authority in favor of historically located contingencies that make pedagogical sites of production so rich for all participants. In oral history interviews, which traffic in the recreations of memory, interpretation, and reconstituted meaning, the subject and its narrations are never the same. Each point is crucial for theatre and performance students examining their own activities in the field. I find that students instantly warm up to the recognition that fields exist and are transmitted through networks of living relationships and contingencies, repetitions and adjustments, affinities and differences, rememberings and forgettings.

For Portelli, the radicalizing intervention of oral history lies in the recognition of its narrative attitude, that it is a historiographic practice, in that "the narrator is now one of the characters, and the telling of the story is part of the story being told. This implicitly indicates a much deeper political and personal involvement than that of the external narrator." 11 Theatrical action lies in the production of knowledge itself. In order to apprehend it, students learn to attend written and oral narratives, as well as the everyday textualities of space, time, and gesture, a concept well within the reach of the student of performance. Hence Portelli's definition - and his practice - suggests several methods of apprehending the possibilities of oral history: as a person, character, and performer. Whereas the classical, abstracted oral historian interviews (or amuses, harasses, or bores) his subject, for Portelli the goal is to acknowledge the oral historian as always already part of the history at hand. Here the voice of the oral historian produces the body of research in dialogue with the interviewing subject(s). Participants are not simply 
involved in a discussion about objects of knowledge, but invested in the capacity to assess the living history of knowledge production. Dynamic discussions emerge when differently located voices are empowered to speak about objects with shared authority. For theatre and performance, where ideological formations sometimes force psychic splits between theory and practice in student research, the concept of a shared authority acknowledges as complex the research environment that we find ourselves negotiating, and as such may provide a basis on which to encourage productive research encounters between interlocutors. While Paul Thompson suggests that oral history "provides a means for radical transformation of the social meaning of history"12 at large, this deliberate attention to narrative attitude makes oral history an especially promising tool in artistic settings. The goal is to provide students with tools to make their research activities "speakable."13

Through several iterations of the course, I have found students impassioned about learning how to listen to the research environments they find themselves working in, and to the ways that they, their peers, their professors, and artists respond to them. Suddenly, theory really is practice. ${ }^{14}$ At NYU, Arthur Bartow's edited collection Training the American Actor provided timely narratives about actor training traditions, as well as insights into the institutionally powerful voices that transmit them. ${ }^{15}$ For example, students have the chance to read the relationships between what Mary Overlie writes about teaching the Viewpoints, how different teachers approach the Viewpoints, and how student artists respond - none of which need be prescribed toward a single goal or product. Interviews with faculty from the studios and from academia alike supply students with a range of perspectives for their research projects. At Macalester College, a liberal arts institution where students have less exposure to studio training (and their luminaries), Bartow's text offers only one of several models for learning about histories of artistic technique. It is encouraging that journals and publishers increasingly make available texts that document the working processes of theatre and performance practioners and theorists. At a liberal arts institution students more frequently seek out and work with non-residential artists as either a complement to their artistic training on campus, part of a community-based learning commitment, or a scholarly engagement with artistic production. In both BFA and BA programs, listening to oral history archives (Yale University's American Music collection, for example) helps students hear the nuances between recorded oral histories in which interviewers and interviewees speak across research communities. We listen for gaps as much as we do for connections. The Yale collection is a productive site, though only if those in higher education understand musicians as a "research community" no less important than an academically transmitted field of music (and vice-versa).

Listening to each other interpret the sounds and demarcations of such archived interviews moves students to articulate, in a very immediate way, the interpretive risks and rewards of research in oral history. Listening to their own in-class 
conversations, through informal interviews and trial recordings, produces yet more detailed student awareness of the tenuousness of voice itself within the matrices of discourse. "I meant to say," "I heard you say," and "I was thinking" frequently repeat in introductory sessions of the semester. The moment of the interview is always paramount. So too is the interview duration, as time prescribes form. The number of interviews indicates the kind of dialogue which might become possible between interlocutors. For this class, students are advised on a case-by-case basis in order to help them facilitate the widest navigational control for their projects - and learn their feasible limitations. As a rule, students approach interviewees only when they are ready to conduct an informed conversation about the work and background of their subject. ${ }^{16}$ Thus, the first quarter of the semester is dedicated to the study of oral history theory and method, as well as an initial exploration into possible research topics. During the second quarter students commit to and research their topic in preparation for interviewing, a process that involves drafting interview questions (considering the ethics of what to ask and what not to ask). The third quarter provides an intense seminar community for discussing and reflecting upon student experiences in the field, linking the insights of disciplinary theory and practice. In the concluding quarter students further address questions of transcription, editing, authority, and authorship. The final product for the class is a thirty page three ring binder, made up of at least three sections documenting the interview, research for it, and the semester's homework assignments, responses to readings, and field notes. Usually students produce additional files to display creative design and documentation techniques, from photographs of an artist's work, to correspondence between interlocutors, email texts, poems, and other yarns. This work can lead to another project. This could mean, for example, integrating examination of an experimental artist's work into a future production; a choreographer's deploying of the visual arts; studying a dance technique that changes a poet's approach to writing; a costume designer's study of the institutional history (and future) of the field; a community-based theatre's strategies for activism; launching a documentary theatre project. Clearly, the course requires significant ability and commitment from an undergraduate to sustain independent research with the support of the seminar participants, as well as in-depth mentoring by the professor. Over a student's career, the goal is to advocate for the possibility of listening to and transcribing student and artistic voices, in the contexts of charged research environments.

NYU professor Carol Gilligan's attention to university teaching and mentoring practices suggests the importance of reckoning with "the relational climate of the research encounter." 17 Her research continues to address the costs of initiation and describes the task of developing alternative research methodologies as indeed involving a "return to sites of necessary losses." In this line of thinking, such sites are aspects of the initiation into social order, or the sacrificing of voice in order to enter a discipline, by becoming a member of its community, and being socialized 
to its norms. Those whose voices are inadequately disciplined risk compulsory expulsion from the field, or at least perpetual marginality; yet Gilligan imagines that to do otherwise is to invite even greater risk. This points to the peculiarly alienating effects of institutional learning, in which, Gilligan says, "we're trained not to ask our real questions, and not to know what we know." Paulo Freire frames the question as one of pedagogical and institutional failure, against which students rightfully rebel. ${ }^{18}$ One way for undergraduates to rebel against stultifying frameworks of the research environment is to leave it. Another is for them to cling to its old bipolarities, with theory on one side, practice on the other, perpetuating the trauma of divorce. Freire's and Gilligan's research supports the need for continuing investigation into ways that teaching and research methodologies in theatre and performance produce liberating and empowering encounters in arts education, prioritizing the ethical practice Gilligan identifies as "listening for a voice, in students, which may be held in silence."

While institutionalized fields aim to reproduce themselves, there is no consensus in theatre and performance studies as to how to engage this reproductive drive. At the same time that fields like theatre and performance "inhabit" (and inhibit) faculty and students, we can nurture that sense for tenuous acts of disciplinary habitation. Oral history can contribute to the way theatre and performance studies pursues practice-based research agendas, described by Bruce Barton as

a thoroughly integrated approach and set of strategies. This implies constant, mutual, and reciprocal influence between the artistic practice and the research activities [in which] the devising process encourages a high level of self-reflection and awareness: reflection in pre-established learning and awareness of levels of unlearning and new language. ${ }^{19}$

I find this an inspiring "relational climate of the research encounter." A practicebased research (PBR) model recognizes the arena of theatre and performance, combining intellectual inquiry with creative practice as well as a sense for all its living histories, with its own oral cultures and languages. Everyday rehearsals of theories and practices infrequently translate into printed formats (hence more traditionally accessible for academia), but these knowledges are, to say the least, neither circumscribed by standard academic form nor peripheral to the field. For theatre and performance faculty, finding ways to work with PBR epistemologies, rather than paternalistically accommodating them, requires that we find multiple mechanisms to communicate and interpret the habitus of their skilled mediations, oral and otherwise ${ }^{20}$ While oral history privileges spoken discourse, it encompasses gestural, sonic, and finally somatic ensembles as well. ${ }^{21}$ Herein lie challenges and promises, as Kris Salata's question confirms: "How might theatre scholars engage 
in productive dialogue with practical artistic researchers, without falling into conventional forms of critique that reify problematic dynamics of authority?"22 The question is an important one, because the data, or the form information takes, is a mode of authorization that consolidates power. Oral history can be a technique for observing and critiquing the production of knowledge discourses that circulate in the domains of orality and may bear on transcriptions of the written.

Given that oral histories in the theatre and performing arts supply primary sources about its practices, they may be also used to invite reflection on the critical exchanges that define creative work. Thompson suggests that

the co-operative nature of the oral history approach has led to a radical questioning of the fundamental relationship between history and the community. Historical information need not be taken away from the community for interpretation and presentation by the professional historian. Through oral history the community can, and should, be given the confidence to write its own history. ${ }^{23}$

Experience, in other words, yields its own "local" archives, and the interpretation of these materials need not occur in isolation from the broader community of relevant interlocutors. For theatre and performance, rethinking the standards of research activities, and arts researchers' ways of writing are always pressing assignments. Whose narratives define the parameters of research, and how are these narratives located in relationship to one another? Oral history methodologies can be used to make explicit the heteroglossia of practice-based theatre and performance research.

Lee Haring argues for the place of orality in a true comparative studies, touching on a disciplinary struggle that is also always a political struggle. ${ }^{24} \mathrm{Ngugi}$ Wa Thiong'o details the struggle in the paradigmatic story of the 1968 abolition of the English Department at Nairobi University. Part of the challenge then (and now) was to locate the knowledges, the shared authorities - the narrative attitudes of knowledge production - within a context where orality was suppressed in curricula that simultaneously prioritized a colonial imagination, a hierarchical power structure, and the literary against the local knowledges of Kenya's oral cultures. What has grown out of that historically specific struggle are some of Ngugi's most enduring contributions for thinking more broadly about the field of theatre and performance research activities - namely, the social contestations of orality, orature, and performance in institutionalized and institutionalizing spaces:

The performance space is also constituted by the totality of its external relations to these other centers and fields. Where are they all located relative to each other? Who accesses these centers 
and how frequently? [. . .] The real politics of the performance space may well lie in the field of external relations; in its actual or potential conflictual engagement with all the other shrines of power, and in particular, with the forces that hold the key to those shrines. ${ }^{25}$

Ngugi's exhortations locate the arc of performance productions as travelling not simply through its designated places of preparation and delivery, such as the classroom, studio, or stage, but rather through all the shrines of power that mobilize (and deter) the processes of creative work that eventually constitute an event of performance in whatever form it may take. Moving between orality, performance, ideology, and theory is not a self evident process (to say the least), but the theatre and performance studies community should embrace the challenge. With characteristic precision, Trinh T. Minh-ha locates some of the trouble when she addresses "the dilemma of crossing borderlines." She observes:

Academics, infatuated with their own normalization of what constitutes scholarly work, abhor any form of writing that exceeds academic language and whose model of theorizing is not recognizable, hence not classifiable as "theory," according to their standard of judgment. [I want] to show how theory can relate intimately to poetry; how they interact when meaning is prevented from becoming dogma. ${ }^{26}$

Ngugi and Trinh share the concern about how certain forms of authority foreclose others.

In this one semester course, "The Oral History Project," students contemplate this foreclosure of shared authority, between orality and the written record, and theory's place in artistic community practices. Remembering Portelli's concept of narrative attitude, students again address their methods for transcription and interpretation of their oral histories, paying attention to how the document invents and transfers positionality and power. In this way, students can begin asking the gentle, if undeterrable, questions: what are the distinctive idioms and narrative forms that sustain the living histories of the places they work in, be it experimental theatre, tech track, or theatre studies? How will they decide to represent the field of external relations that drive pedagogical and research practices? How do institutional discourses locate student research? What are the responses to such institutional formations, from within and without? Actors, directors, playwrights, and faculty who are not primarily employed by institutions of higher education supply students with valuable perspectives for imagining the range of possibilities for navigating their professional futures. Hopefully students begin a careful critique of their own 
educational locations. Such questions can encourage students to pause, in their notoriously over-busy schedules, to grasp the sheer power of the languages and social imaginings that permeate their fields of training, both academic and artistic. At root is the desire to help students fully enter into these historically located creative and critical dialogues, rather than remaining passive receptors of their norms.

Della Pollock announces in Remembering: Oral History Performance (2005) that oral history has become a highly productive center of theatre and performance research, in a variety of locations. ${ }^{27}$ Pollock's work has led her to examine "oral history as performance in performance." As an explicitly democratizing method of research, oral history appeals to issues of narrative authority by engaging a variety of speakers as knowing subjects in the dynamics of dialogue. ${ }^{28}$ Thus, "The Oral History Project" works with students on those threshold places of orality (between silence, speech, and writing) before the institutionalizing laws of theatre and performance training confer both academic and artistic credentials. It is an advocacy project to help students locate their work and their studies, and, above all, inscribe their voices in the living histories of the multidisciplinary theatre and performance arts. It aims to lend students, as members of the creative community, the opportunity to listen, look upon, and speak about their work and their field.

Of course, Walter Benjamin warns that "in every era the attempt must be made anew to wrest tradition away from a conformism that is about to overpower it." ${ }^{29}$ A glance at the archives begs the most obvious questions for the legacy of oral history in theatre and performance research. The most accomplished and essentially privileged of scholars (as privilege is always a measure of access) enjoy engaging with living artists about their craft but also understand the importance of developing their own position and techniques for interviewing, dialogue, and the power of relationships in the research encounter. These interpretational activities for theatre and performance research are crucial for the field and for careers. Why would faculty not, as a matter of course, prepare students with the methods and theories to participate thoughtfully in this kind of research? The small liberal arts college can confer such training (and confident social standing, the subject of power) to students who may engage in whatever they desire with due specialization. In the context of a field where professional and liberal arts degree training programs may in fact turn out to be terminal degrees, as is often the case for students in theatre and performance, training students to engage others critically through the studied oralities of dialogues, interviews, and field work-involving the highly nuanced intersubjective interpretations, interpellations, and written transcriptions-is, in sum, an urgent priority.

At the same time, oral history (as a form of documentation, broadly speaking) is legion throughout popular culture, the arts, and the academy. What play, performance, film, or novel is not based on the "interview," which is only a new 
research approach for some (rather green) thinkers and practitioners? "Perhaps the greatest danger," longtime oral historian Michael Frisch observes of the sometimes fitful explorations into his field, "is [this] fascination with new methodology, which makes exciting new forms of evidence seem to exhibit self-evident and unequivocal significance. ${ }^{{ }^{30}}$ Given such caution, theatre and performance studies will need to develop its own criteria for conducting and assessing the documentation of oral and field research practices. Understanding those archiving processes in the context of theatre and performance research is always bound up with Ngugi's profound insights about disciplinarity, power, and performance. These are essential questions that I will not rush to answer here. I want to emphasize that training students to work the field with oral history reconfigures the theatre and performance research environment in a way that authorizes students to engage languages and practices with a narrative attitude that deploys other kinds of authority. Most pressingly, the cardinal ethic of collaborative work in oral history asks students to assess positionality and difference, granting to students the control of "selecting and shaping testimony," so that they actively engage with the consequences of the fact that "historical discourse remains firmly in the hands of the historian." ${ }^{31}$

\section{Field / Work / Research}

The centrality of orature to all the other systems calls for a reconfiguration and regrouping of the disciplines.

-Ngugi Wa Thiong'o ${ }^{32}$

"The Oral History Project" brings our attention to methodological intersections of practice-based research that faculty in theatre and performance are not regularly trained to deploy, let alone teach: interviewing (traditionally, oral history); field research (traditionally, ethnography); and documentation (from orality to the transcriptions of writing, and from sound to recording). I turn now to address these conjunctions. Consider again the position of undergraduates entering into studies in theatre and performance. Their encounters with practical and scholarly faculties in distinct architectural working spaces, pedagogies, vocabularies, and cultures (from classroom to greenroom) suggest that the field explorations students undertake involve unrecognized, extraordinary conceptual and practical stretches. How do faculty prepare students to engage with such distinctive arenas as the black box, costume shop, fly space, performance theory classroom, and improvisation acting class - to say nothing of the working arts worlds beyond the confines of educational institutions that mesmerize student imaginations profoundly and affect the future of theatre and performance as a field? What kinds of research practices and methodologies do faculty envision for students working across studies in theatre 
and performance, to link their norms and expectations, standards of evaluation, and, not least, relationships to one another? These are difficult questions.

Yet there is another argument to be made, that the student voice in the complexities of theatre and performance research has yet to emerge fully. To paraphrase Paula Giddings, faculty must attend to when and where students enter into the practices of the field. On the one hand, oral history can be used to address the jams and silences produced by tacit knowledges and interpretations. On the other hand, field observation and documentation can detail the knowledges and interpretations themselves. Faculty working with students in this way need to tread a very careful ethical line, though, accompanying students in the ecosystems of artistic living histories without unduly drawing them into the organizational politics that come with it and sometimes raze faculties.

Thinking about student work clarifies theatre and performance departments as rigorously defined constellations of distinctive professional spaces, or ecosystems, which themselves constitute what might be called ethnographic spaces, or sites of field work for student observation, interpretation, and documentation. Framing "The Oral History Project" as a way to address the everyday ecosystem of artistic living histories empowers students in their departmental field assignments and residencies. No doubt, the demands of student learning through participantobservation are complex, but, as oral historians, work in the field involves whatever locations their subjects require. Students move in and out of working spaces, curating, crafting, reflecting, rehearsing, teaching. Each subfield has its traffic and traditions and, as Arjun Appadurai has put it in another disciplinary context, its "disjunctures and differences." Faculty in the arts need not be circumscribed by rumors of anthropological impertinence..$^{33} \mathrm{I}$ take my cue from anthropologist Nicholas Thomas, who argues:

[W] hile ways of observing and ways of representing are often tangled up, and while methods admittedly constrain and influence forms of representation, fieldwork and ethnography are separable. ... [A]t present it helps to situate the enduring problems of anthropological vision in the constitution of the ethnographic genre, while leaving open the potential for another kind of writing energized by the experience of the field. ${ }^{34}$

In other words, it is possible to generate work that "incorporates" ethnographic practice "but is not subordinated to it." For this project, what makes this possible is the methodological grounding in and allegiance to the narrative attitude of oral history. ${ }^{35}$ In practice-based research both interviewing and the reflective, sometimes intensely personal notes of field writing are useful for opening up dialogues within and between disciplinary sites of activity. Students, of course, anticipate 
the possibilities. In addition to writing about their work in practical spaces, and interviewing artistic figures, they also reflect upon their work in academic spaces, interviewing scholarly figures. If "the argument is rather that field work should be drawn into other kinds of writing that move into the space between the theoretical and universal and the local and ethnographic, and that are energized by forms of difference not contained within the us/them fiction [of anthropology], ${ }^{, 36}$ then student projects in this class should not be reducible to either of its two feeder curricula, scholarly and practical, but carve out another, third, space of reflection, theorization, and expression. ${ }^{37}$

In such "active process[es in the] creation of meanings," $" 38$ even misrememberings and "mistakes" afford essential interpretive data. Faculty can direct students to notice inconsistencies in narrative and interpret their meanings - and not simply the inconsistencies of their interviewees, but in their own reflections as well. As Sandy Polishuk suggests, "often the discrepancies tell us more than facts." ${ }^{39}$ What can students learn from the realization that they interpreted the same data in three different ways during the course of a single interview? Or from the way that interlocutors divert and resist narratives of their work (and life) within even the most felicitous of conversations? The deterritorializations of authority that such activities imply are part of the historiographic mission of oral history. Yet Paul Thompson makes very clear that oral history is "not necessarily an instrument for change." ${ }^{40}$ This double consciousness fuels the complexity of attending to the narrative attitudes of oral histories. Whether separately or together, these highly interpretive, polyphonic documents may be applied as primary informational source material for reflection and analysis. ${ }^{41}$

Thinking about theatre and performance as a living history, and about any given department as a local ecosystem in itself, generates an understanding of practice-based research as a series of intimately interlinked historical topographies, yielding an environment whose tempers and events are felt by our students. Again, the question arises: with what tools are students equipped to become active participants in this ecosystem? Ann Elizabeth Armstrong suggests that posing the question addresses curriculum as a site for "place-making" 42 and collaborative exercises between faculty and students. "The Oral History Project" assumes that students are critical, creative, and transformative agents within the field of theatre at large. Theatre and performance research — as well as its pedagogical methods, implemented through the curricula — can help students participate in this poetic ecosystem of artistic weathers, conversations, and debates, and encourage their questioning voices. To my mind, "The Oral History Project," with its attentions to orality, inscription, and interpretation, addresses the ethos of research in the arts.

\section{Feminist Convocations (After Marx)}

"The Oral History Project" takes seriously Marx's concern that "men make 
their own history, but they do not make it just as they please; they do not make it under circumstances chosen by themselves, but under circumstances directly found, given, and transmitted from the past. ${ }^{93}$ Because students in theatre and performance studies do not labor "under circumstances chosen by themselves," faculty must be prepared to interpret institutional interpellations. Addressing differently empowered and authorized participants within the unstable spaces of educational institutions, I have felt what Robyn Wiegman refers to as the strain of a feminist (and indeed, Marxian) imperative: to construct core curricula in order to respond to institutional violence. Wiegman speaks to the challenge for all disciplines, in what she calls "the difficulty of sustaining a relationship to a political and intellectual project that is itself historically transforming and transformative. ${ }^{\prime 44}$ Likewise, it is appropriate to ask how theatre and performance faculties respond to the construction of curricula and research methodologies amidst the persistence of "freedom's oppressive failures." As ever, dialectical discrepancies in the Althusserian "hey, you!" anchor the young artist/student in theatre and performance studies. Entrance into the field provokes what is hoped to be a productive relationship between a student's vision and the cacophonies of ever more professionalizing disciplinary discourses. Perhaps the most savvy enter with a sense of empowerment and the confidence to take advantage of resources and networks, pose questions to peers, faculty, and administrators about what they encounter, and even develop departmental, school, and university initiatives. In an information services economy, as faculty are constantly reminded (by the voice of managerial oversight), such skills are increasingly important for young people to develop. They may even be the entire purpose of institutionalized education. But in the context of an arts education, something more crucial emerges out of this too assuredly pragmatist mix: the task of unpacking the promise of those unstable training processes as sites of exchange between the scholars and artists. This is "the careful project," as Gayatri Chakravorty Spivak has remarked in other pedagogical contexts, "of unlearning our privilege as our loss." ${ }^{\text {45 }}$

I find Hélène Cixous's re-telling of Franz Kafka's parable (from The Trial) useful for thinking hard, once again, about institutionalizing paradigms of theatre and performance research. ${ }^{46}$ In the 1984 university lecture, "A Portrait of the Artist as a Maturing Woman," Cixous situates the young artist within the forceful dynamics of subjectivity and language represented by Kafka's doorkeeper, who stands "before the law." In the story, a man asks for admittance to the law, imagining he cannot do otherwise. The doorkeeper performs what is asked of him and guards the man's petition. After a lifetime of waiting, the man learns that nobody else has waited at the gate for permission to enter the law because, as the doorkeep shouts at him, "this was your own door!" In this way the man fails to imagine his autonomy and in so doing reinstates the law's power. Cixous concludes, 
He will never have known whether the law had an inside. He didn't step in, he didn't go over the threshold, he stayed there all the time. So he did not know anything about the law, that is, he knew everything about the law. All his life he stayed in front of the law, just as the law wanted. So he was in the law without knowing it. And, of course, it was his own door, his own law. ${ }^{47}$

Cixous revisits the parable to unravel the disciplinary propinquities haunting creative practices, adumbrating the ambiguous powers of voice and the word of the law for the disciplined gendered subject. Her reading raises key pedagogical concerns for those who teach and direct research in theatre and performance: the risk is that faculty and students alike secure themselves in Kafka's parable instead of reading its subtle lessons. "We are in front of the sentence exactly as in front of a door, and we don't move. We don't even think about it." "The Oral History Project" works against not thinking about the structures of work that theatre and performance curricula and research methodologies ask students to explore. The Project unlocks the fix of doorkeepings and permissions in order to imagine the possibilities of student research as both art and artifact. If faculty and students are Walter Benjamin's hopeful rag-pickers, then this pedagogical project posits for studies in theatre and performance a mode of inquiry into research practices that trawl through the residues and fragments of everyday activities, and all that must remain disquiet in their wakes. ${ }^{48}$

\section{Notes}

1. This essay is dedicated to Nina Payne, 1921-2006, for her creative work with students and faculty at Hampshire College in Western Massachusetts. I would like to express my appreciation for the suggestions from the editor, and to the readers for their comments.

2. Jane Bacon and Franc Chamberlain, "Editorial: The Practice of Performance Studies in the United Kingdom," Studies in Theatre and Performance 25.3 (2005): 179.

3. J. Ellen Gainor and Ron Wilson, "(Con)fusing Theory and Practice: Bridging Scholarship and Performance in Theatre Pedagogy," Theatre Topics 5.1 (March 1995): 69.

4. Anne Berkeley observes, "Both foundations of the theatre curriculum - the liberal arts and the pre-professional-have been exhausted. Programs are notoriously disjointed and dysfunctional, quagmires of turf battles, ideological discrepancies, and fiscal scarcity. [. . .] The field often suffers, in sum, from a crisis of legitimacy. But educational dispensations are neither monolithic nor neutral, not intransigent but malleable." "Theatre in The 'Engaged University': A Context for Habermas's Communicative Action," Journal of Dramatic Theory and Criticism 22.1 (Fall 2007): 9.

5. I am particularly grateful to Bob Vorlicky for his early support on the project.

6. "The Department of Drama at Tisch School of the Arts is unique in the nation for its combination of rigorous conservatory training and broad-ranging academic education. Using the incomparable theatrical resources of New York City as well as the superb intellectual resources of New York University, the department has created a uniquely balanced B.F.A. (Bachelor of Fine Arts) program that aims to establish the artistic and intellectual foundations for a successful professional life in the theatre and allied disciplines." 18 September $2009<$ http://drama.tisch.nyu.edu/object/DR_Overview.html $>$.

7. Divisions between and within the fields of theatre studies and performance studies manifest in 
several ways. Common to each, the infamous theory and practice divide can be detailed through attention to the genres of work in question: the artifacts and laboratories of theatre on one hand (populated by playwrights, directors, actors, scene designers, and theatre theorists and historiographers, etc.,) and those of performance studies on another (consisting of performance artists, scholars of cultural performance, and performance theorists). Projects in theatre and performance alike run the gamut from canonical to experimental works, although Richard Schechner's outright rejection of the theatre in 1988 in favor of more radical performance serves as the distinctive performance studies springboard for some. Fine arts faculty at universities and colleges devise modes of instruction to advance studies in theatre and performance. Some link theoretical and historical work with studio work, while others exclude one or the other. Relevant departments for the student of theatre and performance might be Theatre Studies, Drama Studies, Performance Studies, Cultural Studies, or any of the language and literature departments, English in particular. Focusing on university and college missions, I do not address nondegree professional training programs.

8. Branislav Jakovljevic, Wade Hollinghouse, and Mark Foster, "Financialization of Education: Teaching Theatre History in a Corporatized Classroom," Theatre Topics 18.1 (March 2008): 70.

9. Jill Dolan, Utopia in Performance: Finding Hope at the Theatre (Ann Arbor: U of Michigan P, 2005).

10. Jill Dolan "Producing Knowledges That Matter: Practicing Performance Studies through Theatre Studies," TDR 40.4 T 152 (Winter 1996): 9.

11. Alessandro Portelli, "What Makes Oral History Different," The Oral History Reader, ed. Robert Perks and Alistair Thomson (New York: Routledge, 1998) 72.

12. Paul Thompson, "The Voice of the Past: Oral History," The Oral History Reader 22.

13. Valerie Yow, “'Do I Like Them Too Much?' Effects of the Oral History Interview on the Interviewer and Vice-Versa," The Oral History Reader 55.

14. The two institutions I have been involved with since beginning this teaching and research project are marked by the legacy of student initiatives in theatre and performance research. Prior to its 2000 premiere at the Denver Center for the Performing Arts, NYU alum Moïses Kaufmann developed an interviewing process for The Laramie Project that resisted the simplistic truth-claiming impetus of documentary theatre elsewhere, preferring instead to examine the fictions of narrative through which interviewers experienced themselves and their interlocutors, predominantly featuring New York artists in the field in Wyoming. Similarly, Macalester alumni Jessica Blank and Eric Jensen used a combination of archival records and spoken testimony (including interviews, letters, transcripts, case files, and the public record) to script an exposé of the criminal justice system in the U.S. The Exonerated tells the stories of six defendants sent to death row for crimes they did not commit. While their techniques differ, what is remarkable is how BFA and BA students have been able to revitalize their own research environments.

15. Consider Michal Kobialka's reflection: “Artaud's Theatre of Cruelty, Brecht's Epic Theatre, Boal's Theatre of the Oppressed, and Grotowski's Poor Theatre attempted to rupture the mneumonic grid of how we think about theatre. Their statements not only signaled a recognition of the existing conditions to expand the limits of language as well as the space of intelligibility, but clearly enunciated the reasons it is necessary to abort current theatre practices and become border crossers." Michal Kobialka, ed., Of Borders And Thresholds: Theatre History, Practice, And Theory (Minneapolis: U of Minnesota P, 1999) 7.

16. Research involving human subjects requires institutional review and approval, particularly in the sciences and social sciences. In the arts and humanities, guidelines for human subjects research frequently do not apply to interviewing activities, especially when it involves populations who are not at risk. In 2004, the American Historical Association issued a judgment to exclude oral history from institutional review, a decision supported by the Oral History Association. Within the first three weeks of the semester, the class examines the issues and causes for ethical review, in order to alert students to select projects accordingly.

17. Carol Gilligan gave two faculty workshops at the Center for Teaching Excellence at NYU, in 2004 and 2006, in which I participated. All quotes are taken from my notes.

18. Paulo Freire and Ira Schor, "A Dialogue About Dialogue," A Pedagogy for Liberation: Dialogues on Transforming Education (New York: Bergin and Garvey, 1987).

19. Bruce Barton, "Intuitive InterPerformativity: Devising and Dramaturgy" Performance as 
Research working group, American Society for Theatre Research [ASTR], Phoenix, AZ, Nov. 2007.

20. Pierre Bourdieu defines habitus as a set of structured dispositions which both frame and allow the subject to navigate action. Outline of a Theory of Practice. (Cambridge: Cambridge U P, 1977).

21. "Orature is not seen as a branch of literature but as a total aesthetic system, with performance and integration of art forms as two of its defining qualities." Ngugi Wa Thiong'o, Penpoints, Gunpoints, and Dreams: Towards a Critical Theory of the Arts and the State in Africa (Oxford: Clarendon P, 1998) 117.

22. Kris Salata, opening remarks, Performance as Research working group, ASTR conference, Phoenix, AZ, Nov. 2007.

23. Thompson 26.

24. At the same time, Haring's suggestion that "using translations and ethnographies, comparative literature can take as its field both oral and written literatures in literary systems around the world" alerts us to the way that literary studies continues to lay claim to arenas of aesthetic production for which its less powerful institutional compatriots in the arts labor, and with far less supported faculties than those in literature, theatre, performance, and the arts. Lee Haring, "What Would A True Comparative Literature Look Like?" Teaching Oral Traditions, ed. John Miles Foley (New York: MLA, 1998) 37. Performance studies, meanwhile, demonstrates its own imperial predilections. "Is Performance Studies Imperialist? Part 3: A Forum" TDR 51.4 T196 (Winter 2007): 7-23.

25. Ngugi 40.

26. Trinh T. Minh-ha, Woman, Native, Other (Bloomington: Indiana U P, 1989) 154.

27. Pollock valorizes "the magnitude of the primary interview encounter by expanding it to include other listeners; rallying its pedagogical force; and trying - sometimes in small measure - to convey the particular beauty of two people meeting over history. It moreover does so live, not only mirroring the primary telling but actively favoring oral history as a mode of embodied knowing - as an epistemology that lives, in Annette Kuhn's provocative words, 'on the pulse: precarious, contingent, sensuous, felt.' Remembering Oral History Performance, ed. Della Pollock (New York: Palgrave, 2005) 101.

28. Notwithstanding the tendency to associate the (potentially) progressive social traditions of oral history practices with its advocacy-oriented counterparts in community-based and other applied theatre practices, I am in fact interested in the uses of the methods of oral history for the work of theatrical practices and narrative research conventions more generally. It is instructive, in other words, when institutions approve alternative research methods for the purposes of community-based theatre, for example, and then object to it when it comes to the proprieties of more traditionally configured arenas of research, be it practical or academic. Clearly, narrative methodology matters.

29. Walter Benjamin, "Theses on the Philosophy of History," Illuminations, ed. and with an introduction by Hannah Arendt (New York: Schocken Books, 1968) 255.

30. Michael Frisch, "Oral History and Hard Times," The Oral History Reader 36.

31. Portelli 72.

32. Ngugi 118.

33. Hal Foster notes "the quasi-anthroplogical role set up for the artist can promote a presuming as much as a questioning of anthropological authority ... an evasion as often as an extension of critique." The Return of the Real (Cambridge: MIT P, 1996) 197.

34. Nicholas Thomas, “Against Ethnography," Cultural Anthropology 6.6 (August 1991): 307.

35. As a social science, anthropology enjoys a privileged status at universities and colleges. Moreover, in the history and practice of the disciplines, the ethnographic goals of anthropology do not necessarily reflect the popular drive of oral historians, including community action, popular memory projects, and the goal of democratizing practices of authorship. See The Popular Memory Group, "Popular Memory: Theory, Politics, Method." The Oral History Reader 48.

36. Thomas 315 .

37. James Clifford approaches writing practices and work in the field as interpretational sites ("what one sees is what one understands"). Fieldwork, then, once regarded as a laboratory for scientific research (and a personal rite of passage) emerges instead as a matrix of intersubjectivity and narrative contestation, in which the pursuit for the control of meaning must remain elusive. In this reading, Clifford's examinations of field-based narrative share with deployments of oral history the attempt to nuance the narrative authority of the subject's voice by prioritizing speakers as situated narrators in 
their own rights.

38. Portelli 37.

39. Sandy Polishuk, "Secrets, Lies, and Misremembering: The Perils of Oral History Interviewing," Frontiers: A Journal of Women Studies 19.3 (1998): 14.

40. Paul Thompson 26.

41. In a sense The Oral History Project involves acts of translation across idiomatic borders. Edith Grossman, translator of Don Quixote, notices that while in the past the traditional praise for a translator might address its seamless verisimilitude to the original text, she argues, by contrast, that the mark of a great translator lies not in the imperceptibility of this labor, but on the contrary, in its distinctions. This suggests that the shared authority of the oral historian's narrative attitude makes not only one (original) author present in the act of transcription, but at the very least two. Among the most challenging tasks to the entire oral history project is the writing of the writer into the work. I find that students are quite comfortable discussing any authority as a distant object to be analyzed and manipulated, even according to the principles of Freud, Brecht, or Foucault. In conducting, transcribing, and interpreting oral history interviews and field work activities, however, students develop their skills as self conscious media apparati. That narrative authority does not pretend to eliminate the interpretational, or translating, role of their own ways of seeing, hearing, and speaking.

42. Ann Elizabeth Armstrong, "Paradoxes in Community-Based Pedagogy: Decentering Students through Oral History Performances," Theatre Topics 10.2 (September 2000).

43. Karl Marx, "The Eighteenth Brumaire of Louis Bonaparte," The Marx-Engels Reader (New York: Norton, 1972) 595.

44. Robyn Wiegman, "Feminism, Institutionalism, and the Idiom of Failure," differences: A Journal of Feminist Cultural Studies 11.3 (1999): 120.

45. Gayatri Chakravorty Spivak, "Criticism, Feminism, and the Institution," Intellectuals: Aesthetics, Politics, Academics, ed. Bruce Robbins (Minneapolis: U of Minnesota P, 1990) 163.

46. Franz Kafka, The Trial (New York: Knopf, 1937).

47. Hélène Cixous, "Reaching the Point of Wheat, or a Portrait of the Artist as Maturing Woman," New Literary History 19.1 (Autumn 1987): 1-21.

48. Harry Harootunian, History's Disquiet: Modernity, Cultural Practice, and the Question of Everyday Life (New York: Columbia U P, 2000). 